\title{
Developing an instrument to measure the adoption of mobile services
}

\author{
Shang $\mathrm{Gao}^{\mathrm{a}, *}$, John Krogstie ${ }^{\mathrm{a}}$ and Keng Siau ${ }^{\mathrm{b}}$ \\ ${ }^{a}$ Department of Computer and Information Science, Norwegian University of Science and Technology, \\ Trondheim, Norway \\ ${ }^{\mathrm{b}}$ Department of Management, University of Nebraska-Lincoln, Lincoln, NE, USA
}

\begin{abstract}
Currently, there is no standard instrument for measuring user adoption of mobile services. Based on the mobile service acceptance model, this paper reports on the development of a survey instrument designed to measure user perception on mobile services acceptance. A survey instrument was developed by using some existing scales from prior instruments and by creating additional items which might appear to fit the construct definitions. In addition, a pilot study was conducted by distributing the survey to 25 users of a mobile service called Mobile Student Information Systems. As a result, a survey instrument containing 22 items were retained. Furthermore, the results showed that the reliabilities of all the scales in the survey instrument were above the target acceptance level
\end{abstract}

Keywords: Survey instrument, trust, context, mobile service, mobile services acceptance model, measurement

\section{Introduction}

Along with the popularity of mobile devices and successful commercialization of mobile communications network, mobile commerce has become more and more prevalent. Mobile commerce [52] refers to the new types of e-commerce technologies, conducted through mobile devices using wireless telecommunications networks and other wired e-commerce technologies. Due to its inherent characteristics such as ubiquity, personalization, flexibility, and dissemination, mobile commerce promises business unprecedented market potential, enhanced productivity, and high profitability. Hence, network designers, service providers, vendors and application developers must cautiously take the needs and considerations of various users into account to provide better services and attract them to mobile commerce [47].

Mobile commerce involves mobile services, mobile technologies, and business models. With the evolution of mobile technologies and the appearance of new innovative business models, we are seeing the growth of mobile services in people's everyday life [7]. Mobile services provide an entirely new way for services providers to better serve their users through a variety of mobile devices over a wireless network in a wireless environment. Mobile services will enable users to make purchases, request services, as well as access news and information using mobile devices. Some key features of mobile services are: mobility, reachability, localization, personalization [35,54].

\footnotetext{
${ }^{*}$ Corresponding author: Shang Gao, Department of Computer and Information Science, Norwegian University of Science and Technology, Sem Sælands vei 7-9, 7491 Trondheim, Norway. Tel.: +47 735 50241; Fax: +47 735 94466; E-mail: shanggao@ idi.ntnu.no.
} 
Customer attitudes and intentions to adopt new mobile services are crucial when introducing new mobile services. In most cases, the successful diffusion of new mobile services is partially determined by whether potential users are willing to adopt the services. Today, mobile services are more and more popular all over the world. However, only a few new mobile services have been accepted by most consumers. Therefore, it is critical to develop an instrument to study the adoption of new mobile services. The benefits are twofold: vendors can better understand the needs of potential consumers, while developers can apply feedback from the developed instrument into their design and implementation process to create a better mobile service.

Significant progress has been made over the last decade in explaining and predicting user acceptance of information technology (e.g., Web-based applications) [23]. However, there are only a few studies that address the acceptance of mobile services. Furthermore, while there has been a great deal of research on mobile services development (e.g., $[11,26,50])$ and mobile and wireless networks (e.g. $[17,68])$, there has not been too much research concerning the potential factors which would affect user adoption of mobile services. Only a small number of these studies focus on the development of an instrument to measure the adoption of mobile services. Most of the studies focus on reusing some measurement items from previous research to measure user behaviour or intention to use.

The main objective of this work is to develop a survey instrument to measure the adoption and acceptance of mobile services. Based on prior analysis of technology assimilation and acceptance of mobile services using existing technology acceptance theory, a research model, which is called mobile service acceptance model in [22], was created to investigate the acceptance of mobile services. The research model includes some antecedents that many studies did not address. We suggested some new constructs, such as context, trust, personal characteristics and initiatives in addition to more traditional constructs (perceived usefulness, perceived ease of use, intention to use) taken from the Technology Acceptance Model (TAM). To operationalize the research model, survey items have been developed to measure each of the constructs.

This paper is organized as follows. In Section 2, we give a brief overview of related work. The research model is presented in Section 3. Section 4 describes how we developed and refined the instrument to measure the research model. A discussion is made in Section 5. Section 6 addresses the practical implications and limitations. Section 7 concludes this research work and points out some directions for future research.

\section{Literature review}

Mobile business, which can be called the next generation of e-business, is more and more common in today's society. Mobile services will change the way people live, play, as well as how businesses conduct transactions. The trend of mobile business will be toward increased real-time interaction between companies and their customers, employees and suppliers [27]. Mobile business can also be interpreted as the utilization of mobile technologies to improve or extend existing business processes.

Today, more and more mobile services are available on mobile business market. However, the adoption of mobile services has been slower than expected [8]. While some technical constraints, such as screen size and unstable network connection, pose certain challenges for the user to adopt mobile services, we believe that there are other issues that can explain why some mobile services have not performed as expected. Thus, we proposed a mobile service acceptance model in [22], which is presented in the next section. 
Mobile services adoption is a relatively new field of research. When introducing new information technology, it is critical to study the factors that influence user intention to adopt the new services. Developers and vendors can apply this knowledge throughout the design and implementation process to create a better service. Various technology acceptance models and theories have been suggested to assist developers in the evaluation of new software applications. In this section, we review some of the major acceptance models.

Several models have been developed to test user attitude and intention to adopt new technologies. These models include the Technology Acceptance Model (TAM) [15,14], Theory of Planned Behavior (TPB) [1], Innovation Diffusion Theory (IDT) [49], Unified Theory of Acceptance and Use of Technology (UTAUT) [62].

Among the different models that have been proposed, TAM, which is the extension of the Theory of Reasoned Action (TRA) [19], appears to be one of the most widely accepted. TAM has been tested in some domains of e-business and proved to be quite reliable to predict user acceptance of some new information technologies, such as intranet [25], World Wide Web [37], electronic commence [46], and online shopping [23]. There are two primary factors in TAM: perceived usefulness (PU) and perceived ease of use (PEOU), that are of particular importance to determine user intention of adopting a new technology or information system. PU is defined as the degree to which a person believes that using a particular system would enhance his or her job performance [14]. PEOU is defined as the extent to which a person believes that using a particular system would be free from effort [14].

Ajzen proposed the Theory of Planned Behavior (TPB) [1] which helps us to understand how we can change the behavior of people. The TPB is a theory which predicts deliberate behavior, because behavior can be planned. According to TPB, human action is guided by three kinds of considerations: behavioral beliefs, normative beliefs, and control beliefs. And an individual's behavior can be explained by his or her behavior intention, which is jointly influenced by attitude, subjective norms, and perceived behavior control. Attitude refers to an individual's positive or negative evaluation of the performance effect of a particular behavior. Subjective norms refer to an individual's perceptions of other people's opinions on whether or not he or she should perform a particular behavior. Perceived behavioral control refers to an individual's perception of the presence or absence of the requisite resources or opportunities necessary for performing a behavior [3].

Innovation Diffusion Theory (IDT) is a well-known theory proposed by Rogers [49]. In recent decades, IDT has been widely used by IS researchers [28]. IDT includes five significant innovation characteristics: relative advantage, compatibility, complexity, trialability, and observability. These characteristics are used to explain the user adoption and decision making process. They are also used to predict the implementation of new technological innovations and clarify how these variables interact with one another. Innovation diffusion is the process in which an innovation is communicated through certain channels, over time, among members of a social system. The theory explains the process of the innovation decision process, the determinants of the rate of adoption, and the various categories of adopters. The theory aims at predicting the likelihood and the rate of an innovation being adopted by different categories of adopters.

Unified Theory of Acceptance and Use of Technology (UTAUT) [62] aims to explain intention to use an IS and subsequent usage behavior. The theory holds that four key constructs (performance expectancy, effort expectancy, social influence, and facilitating conditions) are direct determinants of usage intention and behavior. Gender, age, experience, and voluntariness of use are posited to mediate the impact of the four key constructs on usage intention and behavior. The theory was developed through a review and consolidation of the constructs of eight models that earlier research had employed to explain IS 
usage behavior (theory of reasoned action, technology acceptance model, motivational model, theory of planned behavior, combined theory of planned behavior/technology acceptance model, model of PC utilization, innovation diffusion theory, and social cognitive theory). Subsequent validation of UTAUT in a longitudinal study found it to account for $70 \%$ of the variance in usage intention.

Although the TAM was original proposed for information technology, it is also useful in explaining the adoption of other technologies. However, a single model could not cover all construct which would potentially affect users' intention to use of various new services or technologies, particularly in the mobile business environment. Many adoption models (e.g. TAM), which are used to assess user adoption and acceptance of new information technology, focus on technology aspects. We believe that a more thorough understanding of mobile services adoption needs to take some additional factors into account. Many researchers have suggested that TAM needs to be given additional variables to provide a stronger model [39]. Some researchers have noted that the major constructs of TAM cannot fully reflect the specific influences of technological and usage-context factors that may alter users' acceptance [42]. Davis himself also argued that future technology acceptance research needs to address how other constructs in various situations or settings affect usefulness, ease of use, and user intention to use [14]. Therefore, PU and PEOU may not fully explain people's intention to adopt mobile services. As a consequence, TAM has limitations when investigating user adoption of mobile services, which is also confirmed by prior research [65]. TPB includes some constructs which do not appear in TAM (e.g., perceived behavioral control). However, TPB is not specific to Information Systems (IS) usage. Previous research [58] also points out the similarity between the constructs of TAM and constructs of IDT. The relative advantage and complexity constructs in IDT can be considered as perceived usefulness and perceived ease of use in TAM respectively. But not much research has been done on applying IDT to the domain of mobile services. In addition, although UTAUT unifies more factors and consolidates the functions of the technology acceptance model with the constructs of eight prominent models in IS adoption research, it increases the complexity of its structure, which makes it a little bit complicated to use.

While acceptance and adoption of IT services has been one of the most prevailing IS research topics (e.g., $[15,58,61])$, the pervasiveness of mobile business raises new questions in exploring the adoption of mobiles services, such as what are the key factors determining the adoption of mobile services, and how context factors affect user adoption of mobile services. In addition, to measure and improve the quality of a mobile service, it is necessary to understand what customers really want from and expect of mobile service $[34,44,51]$. Because of these factors, some research models and conceptual frameworks were proposed to explore the issues of mobile service adoption. In [65], the authors presented an extended technology acceptance model that integrates the compatibility from IDT, perceived risk and cost into TAM to investigate what determines user mobile commerce acceptance. They also found that the most important determinant for behavioral intention to use is compatibility. In [9], by expanding TAM and IDT, they presented a research model that examined the factors which determine consumer acceptance of mobile payment. Significant support for the model was found in the data collected from a survey of 299 potential mobile payment users. In [38], they proposed contextual perceived usefulness as a new construct to enhance the understanding of an individual's mobile commence acceptance behavior. It also found that perceived playfulness has a significant effect on behavior intentions, which means that the intrinsic motivational factors are important in building behavioral intention to use mobile services. To our best knowledge, although adoption of mobile services has drawn increasing attention from both academia and practitioners, we have not found any studies which are completely focused on a thorough examination of an instrument to measure the adoption of mobile services. The findings above motivated this research work. 
Table 1

Definition of each Construct in the Research Model

\begin{tabular}{|c|c|c|}
\hline Construct & Definition & Reference \\
\hline Context & $\begin{array}{l}\text { Any information that can be used to } \\
\text { characterize the situation of entities (i.e., } \\
\text { a person, place, or object) that are con- } \\
\text { sidered relevant to the interaction be- } \\
\text { tween a user and an application, in- } \\
\text { cluding the user and the application } \\
\text { themselves. }\end{array}$ & [16] \\
\hline $\begin{array}{l}\text { Personal } \\
\text { Initiatives and } \\
\text { Characteristics }\end{array}$ & $\begin{array}{l}\text { The user's willingness to experiment } \\
\text { with new services. }\end{array}$ & [22] \\
\hline Trust & $\begin{array}{l}\text { The user's beliefs or faith in the degree } \\
\text { to which a specific service can be re- } \\
\text { garded to have no security and privacy } \\
\text { threats. }\end{array}$ & {$[22]$} \\
\hline $\begin{array}{l}\text { Perceived Ease } \\
\text { of Use }\end{array}$ & $\begin{array}{l}\text { The extent to which a person believes } \\
\text { that using a particular system would be } \\
\text { free from effort. }\end{array}$ & [14] \\
\hline $\begin{array}{l}\text { Perceived } \\
\text { Usefulness }\end{array}$ & $\begin{array}{l}\text { The degree to which a person believes } \\
\text { that using a particular system would en- } \\
\text { hance his or her task. }\end{array}$ & [14] \\
\hline Intention to Use & $\begin{array}{l}\text { The user's likelihood to engage mobile } \\
\text { services }\end{array}$ & [14] [19] \\
\hline
\end{tabular}

\section{Mobile services acceptance model}

The mobile services acceptance model [22], as it is shown in Fig. 1, is an extension of the technology acceptance model (TAM). In addition to perceived ease of use and perceived usefulness, the mobile services acceptance model includes trust, context, and personal initiatives and characteristics factors to study user adoption of mobile services. Table 1 summarizes the definition of the variables in the mobile services acceptance model.

Since some new constructs were added into the original TAM model, a brief description of those constructs is provided here. Context provides an understanding of the way and circumstances for performing an activity [6]. Mobile services are often developed to provide an alternative channel for accessing services, not to replace the existing channels completely. The use of mobile services is able to provide time and place independent service access, which is incorporated in the context construct in our research model. When a service needs to be accessed immediately regardless of time and place restrictions, the usefulness of the mobile service is perceived as the highest, so that it would implicitly influence user intention to use the service. Because a user's concerns and needs vary with the context in which he/she uses a service, the services that can meet the user's needs in a specific context will provide the best value to the user [18]. Therefore, it is believed that user's perception of the ease of use and usefulness of mobile services may vary in different contexts.

Users willingness and needs play important roles in the adoption of mobile services. The organization may encourage their employees to use new information technology by offering rewards. On the contrary, mobile services are mainly designed for individual users, who may have different expectations and needs in accordance with their preferences. Because different users might perceive a mobile service in different ways, their eventual intention to use a mobile service might differ. Moreover, most mobile services are technology based applications, which demand a certain level of knowledge and skills from the users. It may be difficult for people without any technology background to comfortably adopt them. Therefore, 


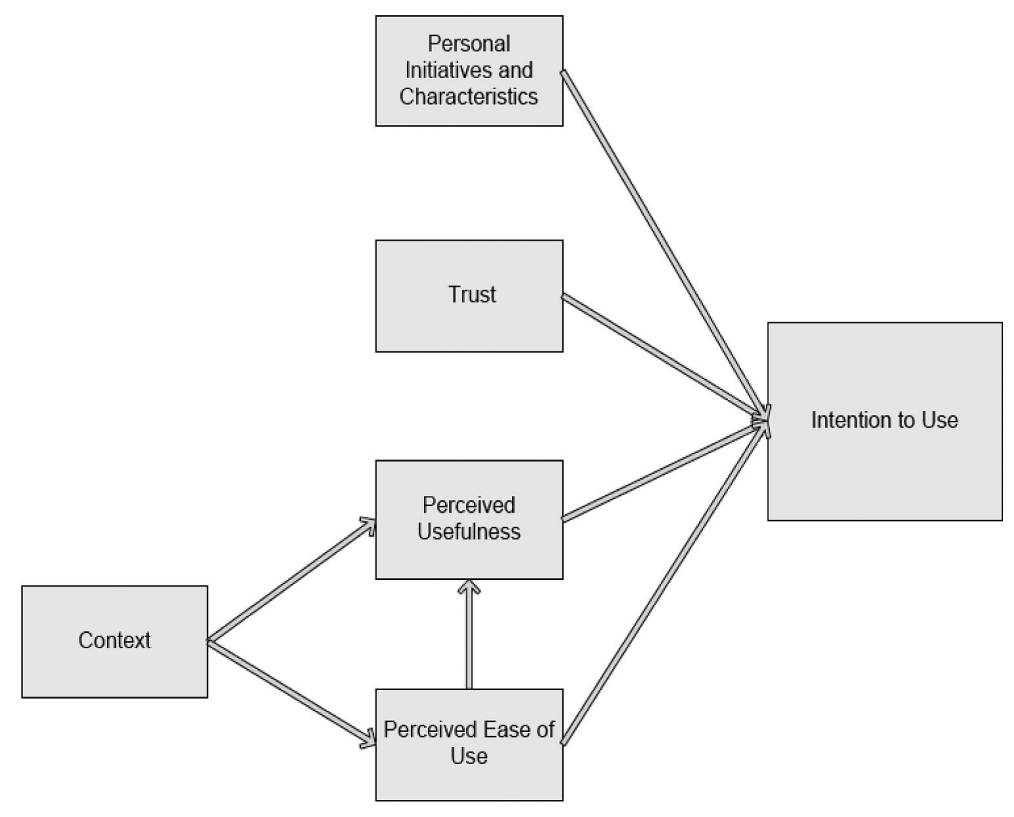

Fig. 1. The Research Model.

we believe that personal initiatives and characteristics have significant influence on the user's adoption of mobile services.

A user's beliefs or faith in mobile services is also important when a new mobile service is introduced to him/her. For mobile service providers, cultivating consumer trust is a time-consuming process. Trust is hard to gain, but it is easy to lose. Many factors may influence customer trust on the process of adoption of mobile services. User perception of security and privacy, and integrity of the application are important antecedents of trust on mobile services. Corporate branding and reputation may also be used to engender trust in the intention to use mobile services.

\section{Scale development}

In this section, the development process of measurement items for all the constructs was described. Creation of appropriate survey items stem from previous literature. Some of our survey items can be selected from the existing scales from prior studies. Further, some items may be developed from discussions on the relevant topics from different pieces of literature [40].

Prior to developing measurement instruments for the research model, the literature was searched for scales that were already developed. After a check on the existing validated instruments, we found that very few studies had explicitly measured the following three constructs in the research model: context, trust, and personal initiatives and characteristics. Therefore, new scales had to be developed for these constructs.

The development of the instrument was carried out in three steps. The first step was item creation, which was to create pools of items for each construct by identifying items from the existing scales, and to create additional items that might fit each construct's definition. The second step was item refinement. Pilot testing with academic staff as well as students majoring in information systems were carried out. As a result of the pilot testing, items with inappropriate wording and ambiguous meanings were refined. 
In the third step, instrument testing was carried out. The instrument was distributed to a small sample of respondents. Scale reliability was analyzed from this test. The analysis of the testing results also provided some insights for further refinement and elimination of items.

\subsection{Item creation}

To develop the initial candidate items for all the scales in the proposed research model, some of the items were adopted from prior studies and modified to fit the domain of mobile services. Previous research works were reviewed to ensure that a comprehensive list of measures were included. In some cases, some new items were developed as none could be found in existing literature, but these new items were also based on conceptualizations and theories in existing literature. In our study, new candidate items were developed for the following constructs: Trust, Context, and Personal Initiatives and Characteristics.

Measures of perceived usefulness, perceived ease of use, and intention to use were adopted from [14, 15]. Specifically, we selected 6 validated items from prior research to measure perceived usefulness and perceived ease of use respectively, and 2 validated items to measure intention to use. In addition to changes in wording in reference to 'performing a task' instead of 'performing a job' to be more generally applicable, some minor words changes were made to elaborate and interpret the statement in the measurement items so that they better fit our mobile service experiment. For perceived usefulness, items fell into three main categories. The first one is related to work or task effectiveness, the second is productivity, the third is related to the importance of the system or service to the user. For the construct perceived ease of use, we followed three main dimensions: physical effort, mental effort, and easy to learn, which are consistent with three main clusters identified in a prior study [14].

The trust construct concerns user's faith in the degree to which a specific service can be regarded to have no security and privacy threats. Many factors may influence people's trust in mobile services, such as the ability to control privacy settings and personal preferences. In addition, a reputable mobile service provider might also help to engender trust. Viljanen [63] defines an ontology of trust. The author created a taxonomy of existing trust models. Thirteen very different computational trust models were analyzed on what information consumers require for them to trust a product. For example, the trustor can trust the identity of the trustee, its actions, the business value of the planned transaction, and the capability of the trustee in performing the specific task. In [53], the authors portrayed a framework to study means of initiating and sustaining customer trust in mobile commerce. They found that building customer trust in mobile commerce is challenging. Thus, it is also important to cultivate online trust [20] in terms of reliable performance of mobile services and the acknowledged reputation of mobile service vendors, especially in the early stages. Our measurement on the construct trust took into consideration trust related factors like security, privacy, belief, which would affect the adoption of mobile services. In addition, this measure also incorporated the element of reputation of service provider which is able to cultivate customer's trust on mobile services. The measure was task focused. This task focused measuring approach is similar to one taken by [10] in measuring computer self-efficacy. The focus for proposing the measurement items in this work was on trust with respect to using mobile services in general. Our suggestions on the trust measurement items mainly followed on the following three dimensions: a) User's trust in the system or service, b) User's trust in the system or service provider (e.g., system provider, software developer), and c) User's trust in his/her own capability to use the system or service. Specifically, we suggested 6 initial items to measure the trust construct (see Appendix 1).

The personal initiatives and characteristics of a user can be defined as that user's willingness to experiment with new services. Some people are more receptive to new technology and innovations 
than others. This has already been explained by the innovation diffusion theory (IDT). We believe that technology diffuses because of cumulative decisions by individuals to adopt it. The perception of the technology is one of the keys to how rapidly people adopt or use new technology. Personal characteristics include the following elements: age, gender, education, knowledge and skills, culture, preferences, etc. A review of the literature was undertaken to identify any existing measures on the construct personal initiatives and characteristics. For example, [30] proposed items to measure the intrinsic motivation to use a computer [59] proposed a model on computing utilization using [60]'s work as a frame of reference. We also include the element of financial incentives [55], which can be seen as an underlying factor that would impact the adoption of mobile services. Our suggestions on measurement items for the construct personal initiatives and characteristics mainly followed two dimensions: a) Perception on using the system or service, b) Motivation to use the system or service. Based on the literature review and our understanding of this construct, a 7-item measure of personal initiatives and characteristics was developed. Some of the items were taken or adopted from prior studies, while the other items were developed specifically for this work.

Context has played an important role in the adoption of mobile services. Some context factors would influence the usage of mobile services. Based on the context, a user can decide whether the mobile services are useful or easy to use. For example, if people have no access to a desktop computer, they will perceive accessing information systems via mobile devices as useful. Prior research [2] found that there were significant differences between experienced users and inexperienced users in the influence of intention to use. In [57], the authors also indicated that, for experienced users, there was a stronger intention to use the technology/service. In this work, we regarded context as a composite construct, which primarily includes factors such as social environment, past experience, and location. The measurement items for the construct context used in the work were generated on the basis of the definition of context and past literature $[16,29,59,67]$. We did not find any past instrument for context which was appropriate for this study. But we did get some ideas about developing the instrument from prior studies. Seven items were therefore proposed for our purpose. Our suggestions on measurement items of the context construct focused on the following two dimensions as discussed in [21]: a) people-centered context, b) place-centered context. People-centered context mainly refers to past experiences that people have, such as other people's attitude and perception of the system. Place-centered context refers to a specific location, what kinds of resources the place has, what kind of environment people are in, etc. The measure for context was also task focused. The respondents were asked to indicate their perceptions of using the system to perform a task in different scenarios.

\subsection{Item refinement}

The initial set of items, generated from extensive reviewing of literature and observation of the various aspects of the constructs in the research model, contained 6 items for perceived usefulness, perceived ease of use, trust and context; 7 items for personal initiatives and characteristics; and 2 items for intention to use. The goals of this step were: a) to increase the construct validity of the various scales being developed, and b) to identify any particular items which still may have been ambiguous or redundant. In order to achieve these two goals, these initial items were presented to two academic researchers in the field of information systems and one graduate student majoring in information systems. First, both the research model and the purpose of the instrument were briefly introduced to them. They were also allowed to ask as many questions as necessary to ensure that they understood the constructs in the research model. Then, they were asked to screen the items for those that did not fit the definition of the 
constructs we provided. This approach is similar to the technique used in the scale development in prior studies [14,43]. The two academic researchers and the student were also asked to rank how well the items fit the construct definition that we provided.

Further, after the two researchers and the student had reviewed the instrument, a meeting was scheduled with one of the academic researchers to discuss the further development of measurement items. During this meeting, the items for all constructs in the research model were evaluated again to eliminate redundant or ambiguous constructs (i.e., those that might refer to more than one construct). The following item from the personal initiatives and characteristics construct is an example of potentially ambiguous items:

"I would like to use the system if its price were lower."

The following items from the perceived usefulness construct are examples of potentially redundant items.

"Using the system would increase my productivity."

"Using the system would enhance my effectiveness."

In addition, the convergent and discriminant validity is another way to verify construct validity. If the placement of the measurement items into the construct categories supplied by the subject was consistent with initial placement of the items, then it was considered to demonstrate convergent validity of the construct, and discriminant validity with the other constructs. During the discussion, the academic staff indicated that most of the proposed items were placed in the right construct category and matched the scale's intent. This demonstrated the convergent and discriminant validity of the constructs. Based on their remarks from both item screenings and subsequent discussions, 5 items were removed, 10 items were reworded, and 5 items were added.

After the described refinement above, a mobile services acceptance survey instrument was generated. The survey instrument included 5 items for perceived usefulness and perceived ease of use, 7 items for trust, context, and personal initiatives and characteristics, and 2 items for intention to use (see Appendix 1).

A typical approach in previous survey instruments [62] tended to be a statement that the respondent was asked to indicate a degree of agreement. In our pilot study reported in the next section, the sevenpoint Likert scales approach, with 1 being the negative end of the scale (strongly disagree) and 7 being the positive end of the scale (strongly agree), was retained to examine respondents' responses in the questionnaire.

\subsection{Instrument testing}

In the third step of the instrument development process, a pilot study was conducted to further assess the validity of measurement items in the survey (see Appendix 1). The reliabilities scales in the survey instrument were examined in a mobile information system, which is called Mobile Student Information Systems (MSIS) [5]. A number of student participants were asked to try out the mobile service in a realistic university campus environment.

The main purpose of the MSIS is to offer a number of mobile services that can assist students in their daily activities in a university campus environment. The system makes use of contextual information such as location, time, and personal preferences to provide the user with relevant and timely information. MSIS consists of three parts: a lightweight client application for deployment on mobile devices, a Webbased portal for system configuration, and a backend server which provides database storage, business logic, and a number of public web services.

Three basic functions offered by the system are listed below: 


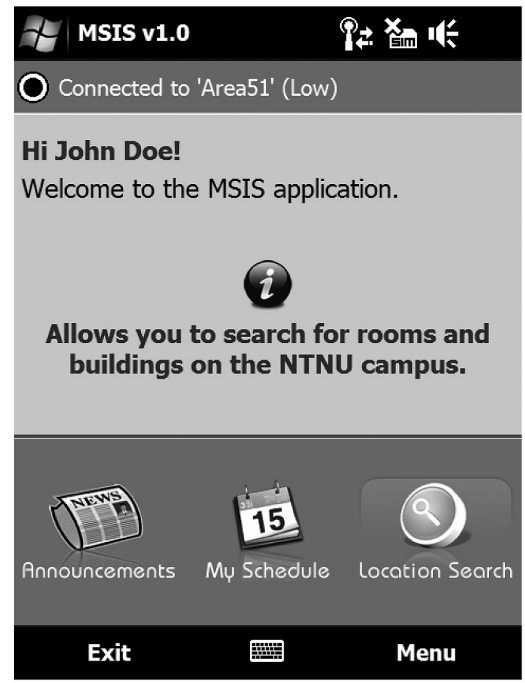

(a) Main menu

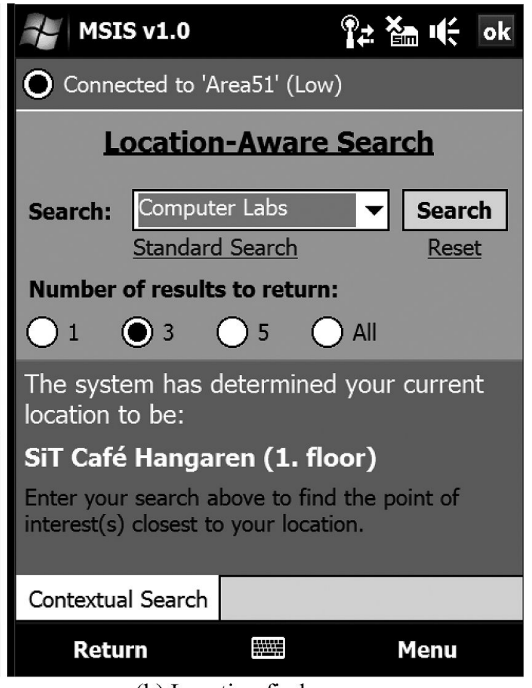

(b) Location finder

Fig. 2. Screenshots of the Mobile Student Information Systems (MSIS).

- Location Finder: Allow users to search for different type of locations on campus, e.g. lecture rooms, computer labs, dining halls, etc. It provides a short description of the location with an option to show the position of the location on a map.

- Lecture Planner: Allow users to view current lectures for a given day or week.

- Announcement: News, notifications, and other information relevant to the user are published on an announcements board. The list supports sorting according to different "flags," such as importance or category.

Figure 2 shows screenshots of the MSIS main menu and the location finder service as they appear on a Windows Mobile 6 Professional emulator. This is quite similar to how it appeared on the actual test devices.

A group of 25 university students were invited to participate in this study. The pilot group consisted of students from various study programs, including students with both technical and non-technical background. Fifteen of the participants were students majoring in computer science, whereas the other 10 participants were students with non-computer science background. Most of the survey participants had at least one mobile device and had some previous experience with mobile services. Students at all levels participated, ranging from first-year undergraduate students to senior graduate students. This diversity among the pilot subjects is expected to produce a more balanced view.

A paper-based survey (see Appendix 1) was distributed to the sample. Prior to completing the survey, all pilot subjects were provided with an information sheet describing the Mobile Student Information Systems (MSIS) and a mobile device with MSIS installed. This way, all participants got some basic introduction to the mobile service. After using MSIS in two specific realistic scenarios in the university campus environment for around 45 minutes, the survey was distributed to all participants. The first scenario refers to the location finder and map services within campus, whereas the second scenario refers to the course schedule service. Respondents were also informed that the data being collected was part of a research study. After filling out the survey, the pilot subjects returned the completed survey to us. A total of 25 completed responses were included in the data analysis. 
The first aim of this test was to access how well the various scales in Appendix 1 can demonstrate appropriate levels of reliabilities. The correlation of items within each scale was used to determine how well the items fit the scales. Items with low item-to-item correlation were identified for elimination. The second aim was to further improve the reliability of the scales. We felt that 33 items might be too lengthy for the respondent to answer - a few participants in our pilot study indicated such. On the other hand, we created a relatively large number of measurement items in the first two steps because we wanted to have the opportunity to develop an enhanced measurement model with higher reliability and validity through this pilot study in the third step. Therefore, in order to keep the length of the survey instrument for future studies reasonable, we hoped to eliminate some items from the measurement items while retaining desired reliabilities and adequately representing the domain coverage of the scales. For scales with more than four measurement items, the target number of measurement items was set to four. Cronbach's ALPHA coefficient [12] was selected to access the Internal Consistency Reliability (ICR) of each construct as it is fairly standard in most discussions of reliability and has been used successfully in other instruments development studies [30] in the field of information systems. According to previous research [48], a reliability coefficient of 0.6 is marked as a lowest acceptable limit for Cronbach's Alpha for exploratory research. Nunnaly [45] indicated 0.7 to be an acceptable reliability coefficient, but lower thresholds are sometimes used in the literature. Kline [33] recommended the minimum requirement for internal consistency as 0.7 . In this study, the target level of minimum reliability coefficient for Cronbach's Alpha was set to 0.7.

Generally, there are two ways to assess the reliability of the scales. The first is to use reliability analysis and reliability statistics. The other technique is factor analysis [32] with the use of principal components analysis to measure the reliability of the scales. Factor analysis usually requests a relatively large sample size. However, in this study, the sample size was small (i.e., 25). Therefore, we decided to use reliability analysis and reliability statistics to test the reliability of the scales. Reliability analysis mainly contains analysis of item-to-item correlation, and item-to-scale correlation. The guidelines below were followed to eliminate some items from the instrument. First, items with low item-to-item correlation were seen as the candidates for item elimination. Then, in order to ensure that domain coverage of the scales would not suffer, a check was made before any item was eliminated. As a result of these two kinds of analysis, some items were deleted from the scales. In this pilot study, the collected data was analyzed using SPSS Version 17.

Looking at the construct trust, item TU1, TU3, TU4, and TU5 were top-ranked four items on the basis of the analysis of computed item-to-item correlations in Appendix 2. Referring to the domain coverage of the construct trust, we found that this item set only covered two of three dimensions of proposed trust domain, including two items (TU3, TU5) on user trust in the system or service, two items (TU1, TU4) on user trust in his/her own capability to use the system or service. In order to improve the representative coverage of the construct domain, the remaining three items were reanalyzed. The only item in this scale concerned with the domain of system or service provider is item TU2. Therefore, we rechecked the respondent answers to item TU2. Only one of the respondents felt that the reputation of the software provider would be a deciding factor for their intention to use the system. Generally, the respondents were less concerned about the provider of the system. Considering most of students likely trust the university as a reputable organization to provide a system/service like MSIS, the responses to this item were understandable. Some students also indicated that they were more likely to pay attention to the reputation of service providers when they were choosing the mobile services in more privacy-sensitive or financial-sensitive settings. In addition, by replacing one of the top-ranked four items (item TU4), which had a relatively low item-to-item correlation, with item TU 2, we found that the reliability score 
of the trust scale dropped slightly compared to the original set. The reliability score for the trust scale decreased possibly because of the non-significance of the reputation of service providers in the university test setting. As a result, for this kind of mobile services, we decided not to improve the representative coverage of the trust domain at the expense of the decreased scale reliability. Therefore, the resulting four-item trust scale is TU1, TU3, TU4, and TU5. We will return to the issue of choosing appropriate set of items for mobile services in various settings in the next section.

In order to select four items to be used for personal initiatives and characteristics scale, an item-to-item correlation analysis on this scale was performed. Item PIC2, PIC3, PIC4, PIC6 were the top-ranked four items. After a check was made to ensure the domain coverage of this scale, we found that this scale domain was well represented by these four items, including PIC 2 and PIC6 with the perception on using the system or service, PIC3 and PIC4 with the motivation to use the system or service. With regards to the eliminated item PIC 1, it was interesting to note that people in general hesitated to admit their own faults, e.g., they wanted to be known to be capable of using the system. None of the participants faced any problems which caused them not to be able to use the system. This outcome can be partially attributed to the participant's personal skills and background. They were all university students and with certain levels of computer literacy. Another finding with item PIC3 worth noting was that those participants who were most eager to use the system early on were technically skilled persons, primarily senior students. In other words, it means people with a technical background are generally more open-minded towards innovative technology.

For the context scale, the top-ranked four items on item-to-item correlation analysis are: CT1, CT4, CT6, and CT7. These items include two (CT1, CT7) from the place-centered context, and two (CT4, CT6) from the people-centered context, which are good representatives of the context scale. Therefore, it was unnecessary to make a further check on eliminated items to ensure the domain coverage of the scale. According to our statistic results, the least important item in the context scale was item CT2. This finding showed that people were generally not affected by others' decisions to use a mobile service or not, provided that the service has a value for them.

For the perceived usefulness scale, item PU3 was proposed to be eliminated due to its lowest rank on the item-to-item correlation analysis. In addition, elimination of the item PU3 did not affect the domain coverage of this scale. Thus, the resulting four-item perceived usefulness scale is: PU1, PU2, PU4, and PU5.

For the perceived ease of use, according to the analysis on item-to-item correlation, the lowest ranked item is item PEOU1. But the domain coverage of this scale would be decreased by eliminating item PEOU1. In order to ensure the representative coverage of the scale, item PEOU3, which is the second lowest weighed in accordance with the statistic analysis, was eliminated, instead of item PEOU1.

Looking at the scale intention to use, since the number of the measurement items is less than four, no item was further eliminated. In summary, several items were dropped and the length of the survey reduced from 33 items to 22 items (as shown in Appendix 1 with asterisks).

Further, reliability statistics on Cronbach's Alpha coefficient were conducted on the survey items used to measure each scale. As shown in Table 2, the reliabilities of all the seven scales after the item eliminations were above the 0.70 level, which meet the target reliability score of 0.70 for this study. These results also indicate that the item eliminations to the scales following the pilot test succeeded in raising the reliabilities of six of the seven scales. Although the reliabilities of the scale perceived ease of use decreased from 0.829 to 0.811 , it is still above the 0.80 level, which demonstrates high reliability of the scale. 
Table 2

Reliability Analysis of Constructs

\begin{tabular}{|c|c|c|c|c|}
\hline \multirow[t]{2}{*}{$\begin{array}{l}\text { Constructs/ } \\
\text { scales }\end{array}$} & \multicolumn{2}{|c|}{$\begin{array}{c}\text { Original } \\
\text { questionnaire }\end{array}$} & \multicolumn{2}{|c|}{$\begin{array}{l}\text { Refined questionnaire } \\
\text { after the item } \\
\text { eliminations following } \\
\text { the pilot test }\end{array}$} \\
\hline & $\begin{array}{l}\text { Number } \\
\text { of Items }\end{array}$ & $\begin{array}{l}\text { Cronbach's } \\
\text { Alpha }\end{array}$ & $\begin{array}{l}\text { Number } \\
\text { of Items }\end{array}$ & $\begin{array}{c}\text { Cronbach's } \\
\text { Alpha }\end{array}$ \\
\hline $\begin{array}{l}\text { Perceived } \\
\text { Usefulness }\end{array}$ & 5 & 0.829 & 4 & 0.835 \\
\hline $\begin{array}{l}\text { Perceived Ease } \\
\text { of Use }\end{array}$ & 5 & 0.829 & 4 & 0.811 \\
\hline Trust & 7 & 0.689 & 4 & 0.743 \\
\hline $\begin{array}{l}\text { Personal } \\
\text { Initiatives and } \\
\text { Characteristics }\end{array}$ & 7 & 0.628 & 4 & 0.769 \\
\hline Context & 7 & 0.622 & 4 & 0.706 \\
\hline Intention to Use & 2 & 0.906 & 2 & 0.906 \\
\hline
\end{tabular}

\section{Discussion}

The research objective of this study was to develop a measurement instrument for our research model, which is an extended version of TAM, in order to assess customer perception of mobile services. The relevance of the additional constructs to TAM in our research model, such as trust and context, has been argued and studied by researchers and practitioners in the field of mobile service adoptions. However, to our best knowledge, few studies have addressed the issue of developing new measurement items for those new constructs. Therefore, a systematic and thorough instrument development process was performed in this research work.

The survey instrument was examined in a mobile service by both undergraduate and graduate students in a real world environment. The university campus context was selected for the following reasons. First, it is easier to solicit users to take part in this experiment by taking the advantage of the existing wellconfigured wireless network infrastructure at the university campus. Second, most previous research work on examinations of user intention to adopt mobile services was based on $3 \mathrm{G}$ mobile value-added services. For example, [41] examined factors influencing the usage of $3 \mathrm{G}$ mobile services in Taiwan, [36] investigated consumer intention to adopt $3 \mathrm{G}$ mobile value added services. What is new in this research is that the users can use the mobile service over either a $3 \mathrm{G}$ network or a Wi-Fi network. As a result, it provides an alternative for users to choose a wireless Internet access method that will best meet their access needs and working styles. Further, several developing countries still have not awarded $3 \mathrm{G}$ licenses and customers are waiting for $3 \mathrm{G}$ services. However, it is possible for them to access mobile services via Wi-Fi networks. Third, this mobile service itself can make use of contextual information such as location, time, and personal preferences to provide the user with relevant and timely information, which is more or less similar to some mobile services in the commercial market. Therefore, this mobile service is a good case for instrument testing and identifying relevant implications for practitioners.

Concerning the research methodology for instrument development, the entire research process was carried out in several phases according to previous research work. In [56], validation of an instrument to measure computer abuse was conducted in four phases: a) pre-test, b) technical validation, c) pilot test, and d) full scale victimization survey. In [31], the instrument for measuring information quality of personal Web portfolios based on the information quality framework were carried out into two major phases: a) instrument refinement (including first analysis: purify the measures and second analysis: 
Table 3

Summary of the entire research process

\begin{tabular}{llccc}
\hline Phase & Technique used & $\begin{array}{c}\text { Content } \\
\text { validity }\end{array}$ & $\begin{array}{c}\text { Construct } \\
\text { validity }\end{array}$ & Reliability \\
\hline $\begin{array}{l}\text { Phase One: } \\
\text { Item Creation }\end{array}$ & $\begin{array}{l}\text { a. Reviewing } \\
\text { Previous Research } \\
\text { work }\end{array}$ & $\times$ & & \\
Phase Two: & $\begin{array}{l}\text { a. Discussion \& } \\
\text { Scale }\end{array}$ & $\times$ & $\times$ & \\
Refinement & $\begin{array}{l}\text { Interview } \\
\text { b. Convergent and }\end{array}$ & & & \\
& $\begin{array}{l}\text { Discriminant } \\
\text { validity }\end{array}$ & & \\
Phase Three: & $\begin{array}{l}\text { a. Item-to-item } \\
\text { correlation }\end{array}$ & & $\times$ & \\
Instrument & b. Cronbach's Alpha & & & $\times$ \\
Testing & & & & \\
\hline
\end{tabular}

refine the measurement model), and b) instrument validation. In [43], development of the instrument was carried out in three stages. The first stage was item creation. The second stage in the process was scale development. The third stage was instrument testing.

The instrument development process involves establishing the scale reliability and validity [56]. The reliability explained by Cronbach's alpha coefficient is the extent to which the measurement scales consistently represent the constructs [24]. The validity refers to the extent to which the measurement scales reflect the variables of interest [13]. There are also some instrumentation techniques available that help researcher to validate an instrument. For instance, factor analysis can be used to ensure scale validity.

In our research work, the procedure in obtaining our final measurement instrument was divided into three steps. The entire research process was conducted in three phases, as outlined in Table 3.

In the first phase, the initial scales were developed from a review of related literature. Some existing scales were adopted for our survey instrument. The research model as shown in Fig. 1 contains some constructs that do not have established instrument items. Items for those constructs were created by us. Where possible, scales from related constructs in IS and other related disciplines were adapted to fit the current context. All these steps were intended to ensure the content validity of the survey instrument. This is similar to techniques used in [43].

In the second phase, to further enhance the scales for content validity, and to identify and correct weaknesses in the initial survey instrument, another examination in the form of the discussion and faceto-face interview with some academic researchers in the field of information systems was conducted. The face validity of the instruments was checked in the following three ways: a) by ensuring the wording in the survey instrument was understandable and appropriate, $b$ ) by pretesting the survey data collection process, and c) by checking the completeness of the items in each construct in our research model. Through the discussion and face-to-face interview, the content validity of the scales was confirmed by all three subjects and some comments were collected from the subjects too. This examination resulted in several changes to the survey items. These changes were incorporated in this study. In addition, the authors examined language translation to ensure that the interpretation of both survey instruments had the same linguistic interpretations for all subjects. Similarly, content validity method such as discussions and interviews were also used to develop and validate an instrument to measure organizational IT [66] and to measure users' attachment to their mobile devices [64]. In addition, the convergent and discriminant validity of the constructs were checked using subjects.

In the third phase, a pilot test of the refined instrument was carried out. The survey instrument was distributed to 25 users comprising both undergraduate and graduate students from one university. Since 
the initial 33 items seemed too lengthy, as indicated by a few respondents, we decided to eliminate some weak items from the instrument while retaining the desired reliability level. The correlation of items within each scale was used to determine which items should be deleted. As a result, some items were dropped and the length of the instrument was reduced. This is similar to the approach that has been used in the study [43]. Furthermore, in order to ensure the reliability of the instrument, a reliability assessment was carried out using Cronbach's alpha. As shown in Table 2, the reliability coefficients for constructs in the refined questionnaire after the item eliminations are above the 0.70 level.

It is believed that the entire development process using different instrumentation techniques helped to improve and ensure the validity and reliability of the instrument. Item-to-item correlation, coefficient alphas, and the convergent and discriminant validity provide evidence for the construct reliability and validity.

Concerning the TU2 in the trust scale, the inclusion of the item regarding the reputation of system or service provider into the trust scale depends on the type of mobile services or experiment settings. We believe that the reputation of system or service provider would significantly influence user trust in the system or service in some special cases. In [69], the authors classified mobile services into the following categories: a) mobile communication, b) mobile information searching, c) mobile transaction processing (such as order placement, payment processing, and inventory management, etc.), and d) mobile office functionality (including calendar, address book, word processing). The MSIS mobile service system tested in our pilot study, which was classified as a personal information-based system, focused mainly on mobile information searching. For this type of mobile service, most users were more likely to pay less attention to the reputation of the system or service provider as their main objective is to get the information they want, so the item (TU2) was not necessary to be incorporated into this survey instrument to measure the adoption of mobile services. However, in some other types of mobile services, where transaction processing or financial-sensitive data are involved, users are more likely to take the reputation of the system or service provider into consideration prior to attempting or adopting the system/service. Some of the participants of the pilot study also indicated that they might be more concerned about the provider of the system or service when they are choosing to adopt a mobile service in financial-sensitive settings. Therefore, the inclusion of TU2 is highly recommended for those survey instruments which are intended to measure and investigate user perception of adopting financial transaction processing involving mobile services.

\section{Practical implications and limitations}

Mobile services have attracted considerable attention in the industry and have shown significant potential and promise for future applications. The findings from this study can provide insights for mobile service providers and help them in assessing customer reaction to mobile services.

According to previous studies on the extension on TAM (e.g., [4]), the focus on expanding TAM has been on technology itself. In our research model, we augmented the view of TAM by including three additional constructs, context, trust, and personal initiatives and characteristics, which were found to be important in predicting user adoption of mobile services. The developed instrument addresses the dimensions and features of those additional constructs that would affect user adoption of mobile services and it is therefore expected to be useful for future mobile service diffusion research. In the pilot study, most respondents indicated that those new constructs would affect their intention to adopt mobile services when new mobile services are introduced to them. From a managerial point of view, the findings in this study indicate that, when developing new mobile services, the developers need to build the services 
by taking all related constructs in our research model into consideration. Mobile services providers are expected to provide the specific service in the specific contextual condition, which is tailored to the needs of the specific user.

The results from the trust construct demonstrates that mobile services developers and providers should cultivate user trust in mobile services by keeping their promises and commitments by ensuring that their services are conducted in line with user needs and expectations - i.e., the services are reliable and risk free. The descriptive results also show that trust and personal initiative and characteristics influence consumers' decision to adopt mobile services. Most respondents also indicated that their perception of context would affect their perception on PEOU and PU. Mobile communication operators and service providers should take these findings into account if they want to distinguish themselves in a highly competitive market.

The student subjects from the university can be viewed as one of the major target markets of mobile services. Thus, results from the pilot study can provide useful insights for mobile services developers and providers. We found that most students have a general interest toward the MSIS services. Students have a positive perception of the MSIS services, and are more likely to start using advanced mobile services. This would suggest that university students, as well-educated consumers, place considerably higher demands on mobile services to meet their specific needs.

With regard to the mobile service used in our pilot study, most previous empirical studies on mobile services adoption and diffusion focused on simple mobile services, such as mobile instant messaging, voice communication, and mobile Web browsing. What distinguishes us from previous studies is that we tested our instrument survey in a relatively advanced mobile information systems with the possibility to provide personalized services and location-based services, which were supposed to provide some new implications for mobile service providers and developers to develop mobile services to increase user intention to use the services.

The scales in our survey instrument can be used as key criteria for those who would like to evaluate their mobile services. The service designers need to pay more attention to the constructs in our research model and instrument. They may get some inspiration from our survey instrument to develop mobile services which can better meet the needs of customers. With regard to recommending this instrument to mobile service providers investigating the acceptance and adoption of other mobile services, in order to ensure the instruments better fit the specific mobile service experiment, we suggest some minor words changes may be needed to ensure easy interpretation and comprehension of the questions in the instrument.

Considering the constant-changing nature of mobile environment, this study offers some insights into understanding the factors associated with mobile services adoption. However, mobile services have several challenges to overcome in order to become widely accepted. Service providers need a better understanding of user perception concerning their belief, initiative and expectations to adopt mobile services in different contextual conditions. The research model and developed instrument can be a good foundation to analyze user demands and desires. We consider that the strength of this article lies in the systematic development of an instrument to access users' adoption on mobile services that has not been well-addressed in a rigorous manner before. We hope that the results of this study can draw practitioners' attention to those factors that may affect user intention to use mobile services besides mobile communications infrastructure.

However, we are also aware of some limitations of our research. First, further research is needed to elaborate the initial conceptualization presented in this paper. As indicated in previous research [31, 56], the confirmatory factor analysis would help to further enhance and improve the validity of the instrument and to establish greater confidence in its findings. This is also the approach we plan to use in 
another round of mobile service testing with a larger sample size. However, the findings from this paper can serve as an excellent starting point for further discussion on future research activities. Second, the sample size in this study can be considered small. Despite the small sample size of 25 respondents, we were able to obtain good Cronbach's alpha for our measurements. Third, the respondents were from a university, which means that the results may not represent views of people outside the university. The generalizability of the results to other potential users remains to be determined. The students also used the mobile service for a limited period of time. Last but not least, the subjects in our instrument testing were students and bias might result from age of the subjects.

Another issue we would like to point out is that it is almost impossible to create an acceptance model which can cover all sets of determinants for mobile services adoption. Completeness and simplicity compete with each other. In our point of view, completeness of the model usually comes at the expense of simplicity of the model. In other words, no simple model can meet all needs. Nevertheless, completeness of model is almost impossible to achieve and is impractical. The survey instrument developed in this research work is based on a research model, which addresses most of important constructs in adopting mobile services as illustrated in previous research works [22].

\section{Conclusion and future research}

This paper described the development process of an instrument for measuring the adoption of mobile services. As a result of the three-stage development process, 22 items were retained for the measurement of acceptance and adoption of mobile services. The paper addresses the issues of instrument evaluation as well as instrument improvement. First, a pretest with some academic researchers was conducted to evaluate the instrument. Then, a pilot study with quantitative data analysis was carried out to further ensure the validity of the instrument and improve the reliability of the instrument. The results from the empirical test of the instrument in the pilot study show that the reliabilities of the items to measure the constructs in the mobile service acceptance model were above the target acceptance level.

The instrument development research for our research model described here offered several contributions. The most important contribution was the creation of a survey instrument to measure the adoption and assimilation of mobile services by consumers. The creation process included surveying known existing instruments, rewording items as necessary, and undertaking a scale development process for the new constructs in our research model. We believe that the systematic approach to the development of the survey instrument would result in a high degree of confidence in the construct validity of the instrument. This instrument could be used to measure and investigate user perception of adopting mobile services. Second, the development process also helped to clarify the definitions of the constructs in the research model. The addition of the new constructs specified to mobile services in the research model ensures that the instrument created is apt to capture user adoption intention of mobile services. Third, the results also further demonstrated the validity and reliability of the two scales (PEOU and PU) adapted from Davis [14]. Last but not least, the findings in this work provided the foundation for future discussions and instrument development efforts on user adoption of mobile services.

There are ample opportunities for future research. First of all, we plan to validate this instrument in another round of study in the near future with a larger sample size. And the other reliability assessment technique, confirmatory factor analysis, is planned to be used to assess the instrument. Second, generalizability of the instrument can be increased by expanding this study to include individuals representing different countries and cultures. Such a study could also help researchers and practitioners to have a higher confidence in the reliability of the instrument. Another suggestion is to expand the 
survey with an additional option to allow participants to write comments about the items. This would serve to further improve the reliability of the instrument.

\section{Appendix 1. Instrument survey}

Mobile student information system

Please use a few minutes to answer the following questions pertaining to the utility, perceived usefulness, usability and general conception of the MSIS service. All respondents remain anonymous.

\section{Perceived Usefulness (PU)}

*PU 1. Using the system would increase the efficiency of my daily work. *PU 2. The system would allow me to find rooms and buildings at NTNU.

PU 3. The system would make it easier to keep track of my weekly tasks.

*PU 4. The system would allow me to better schedule my time.

*PU 5. The system would be useful for me as a student.
Strongly disagree

Strongly agree

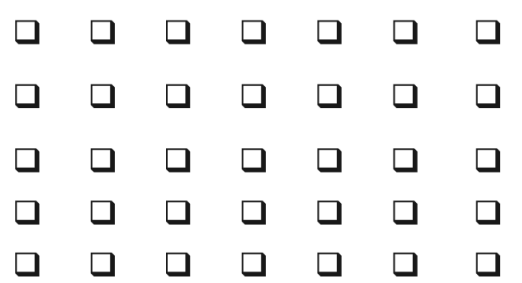

Strongly disagree

Strongly agree

*EOU 1. Learning to operate the system would easy for me.

*EOU 2. I would easily find the information I am looking for using the system.

EOU 3. I would find the user interface of the system clear and intuitive.

*EOU 4. I would find the system to be flexible to interact with.

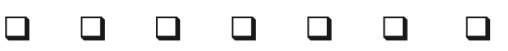

$\square \quad \square \quad \square \quad \square \quad \square \quad \square \quad \square$

$\square \quad \square \quad \square \quad \square \quad \square \quad \square \quad \square$

$\begin{array}{lllllll}\square & \square & \square & \square & \square & \square\end{array}$

*EOU 5. I would find the system to easy to use (user-friendly).

\section{Trust (TU)}

I could use the system...

Strongly disagree

Strongly agree

*TU 1. if I have a clear conception of the functionality of the system.

TU 2. if the system provider is widely acknowledged (e.g., the university)

*TU 3. if the system protects the privacy of its users .

*TU 4. if I feel confident that I can keep the system under control.

*TU 5. if I feel confident that the data returned by the system is reliable.

TU 6. If I believe it is risk-free to use the system.

TU 7. if it is safe to use the system. $\begin{array}{lllllll}\square & \square & \square & \square & \square & \square & \square \\ \square & \square & \square & \square & \square & \square & \square \\ \square & \square & \square & \square & \square & \square & \square \\ \square & \square & \square & \square & \square & \square & \square \\ \square & \square & \square & \square & \square & \square & \square \\ \square & \square & \square & \square & \square & \square & \square \\ \square & \square & \square & \square & \square & \square & \square\end{array}$ 
Personal Initiatives and Characteristics (PIC)

PIC 1. I am capable of using the system.

*PIC 2. I have fun using the system.

*PIC 3. I prefer to be the first one using the system.

*PIC 4. Using the system gives me an advantage over those who don't.

PIC 5. I would only use the system if it was available for free.

*PIC 6. I find it rewarding to use the system.

PIC 7. Using the system is a good idea.

\section{Context (CT)}

I could use the system...

*CT 1. if I am being out of home or the office.

CT 2. if most people around me are using the system.

CT 3. if I had nice experience in using mobile services before.

*CT 4. if the University encourage students to use the system.

CT 5. if the system was easy to obtain and install.

*CT 6 . if it is meaningful/relevant to my daily tasks.

*CT 7. if I did not have access to a desktop computer or laptop.
Strongly disagree

Strongly agree

$\begin{array}{lllllll} & \square & \square & \square & \square & \square & \square\end{array}$

$\begin{array}{lllllll}\square & \square & \square & \square & \square & \square & \square\end{array}$

$\square \quad \square \quad \square \quad \square \quad \square \quad \square \quad \square$

$\square \quad \square \quad \square \quad \square \quad \square \quad \square \quad \square$

$\begin{array}{lllllll}\square & \square & \square & \square & \square & \square & \square\end{array}$

$\square \quad \square \quad \square \quad \square \quad \square \quad \square \quad \square$

口 $\square$ 口 $\square$ 口 $\square$

\section{Intention to Use (IU)}

Strongly disagree

Strongly agree

$\begin{array}{lllllll}\square & \square & \square & \square & \square & \square & \square \\ \square & \square & \square & \square & \square & \square & \square \\ \square & \square & \square & \square & \square & \square & \square \\ \square & \square & \square & \square & \square & \square & \square \\ \square & \square & \square & \square & \square & \square & \square \\ \square & \square & \square & \square & \square & \square & \square \\ \square & \square & \square & \square & \square & \square & \square\end{array}$

Strongly disagree

Strongly agree

*IU 1. Assuming I have access to the system, I intend to use it.

*IU 2. Given that I have access to the system, I predict that I would use it.

$\begin{array}{lllllll} & \square & \square & \square & \square & \square & \square\end{array}$

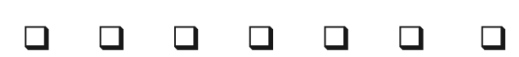

* --- Indicates the remaining items after the item eliminations following the pilot test.

\section{Appendix 2. Item-to-item correlation by scale}

Perceived usefulness

\begin{tabular}{cccccc}
\multicolumn{7}{c}{ Inter-item correlation matrix } \\
\hline & PU1 & PU2 & PU3 & PU4 & PU5 \\
\hline PU1 & 1.000 & 0.477 & 0.385 & 0.541 & 0.616 \\
PU2 & 0.477 & 1.000 & 0.379 & 0.477 & 0.713 \\
PU3 & 0.385 & 0.379 & 1.000 & 0.306 & 0.490 \\
PU4 & 0.541 & 0.477 & 0.306 & 1.000 & 0.531 \\
PU5 & 0.616 & 0.713 & 0.490 & 0.531 & 1.000 \\
\hline
\end{tabular}


Perceived ease of use

Inter-item correlation matrix

\begin{tabular}{lccccc}
\hline & EOU1 & EOU2 & EOU3 & EOU4 & EOU5 \\
\hline EOU1 & 1.000 & 0.690 & 0.375 & 0.281 & 0.326 \\
EOU2 & 0.690 & 1.000 & 0.518 & 0.588 & 0.450 \\
EOU3 & 0.375 & 0.518 & 1.000 & 0.419 & 0.495 \\
EOU4 & 0.281 & 0.588 & 0.419 & 1.000 & 0.774 \\
EOU5 & 0.326 & 0.450 & 0.495 & 0.774 & 1.000 \\
\hline
\end{tabular}

Trust

Inter-item correlation matrix

\begin{tabular}{rrrrrrrr}
\hline & TU1 & \multicolumn{1}{c}{ TU2 } & \multicolumn{1}{c}{ TU3 } & \multicolumn{1}{c}{ TU4 } & \multicolumn{1}{c}{ TU5 } & \multicolumn{1}{c}{ TU6 } & \multicolumn{1}{c}{ TU7 } \\
\hline TU1 & 1.000 & 0.179 & 0.402 & 0.355 & 0.688 & -0.035 & -0.108 \\
TU2 & 0.179 & 1.000 & 0.340 & -0.167 & -0.145 & -0.124 & -0.149 \\
TU3 & 0.402 & 0.340 & 1.000 & 0.286 & 0.329 & 0.462 & 0.391 \\
TU4 & 0.355 & -0.167 & 0.286 & 1.000 & 0.456 & 0.374 & 0.542 \\
TU5 & 0.688 & -0.145 & 0.329 & 0.456 & 1.000 & 0.164 & 0.059 \\
TU6 & -0.035 & -0.124 & 0.462 & 0.374 & 0.164 & 1.000 & 0.758 \\
TU7 & -0.108 & -0.149 & 0.391 & 0.542 & 0.059 & 0.758 & 1.000 \\
\hline
\end{tabular}

Personal initiatives and characteristics

Inter-item correlation matrix

\begin{tabular}{rrrrrrrr}
\hline & PIC1 & \multicolumn{1}{c}{ PIC2 } & \multicolumn{1}{c}{ PIC3 } & \multicolumn{1}{c}{ PIC4 } & \multicolumn{1}{c}{ PIC5 } & \multicolumn{1}{c}{ PIC6 } & \multicolumn{1}{c}{ PIC7 } \\
\hline PIC1 & 1.000 & 0.356 & 0.250 & 0.358 & -0.432 & 0.431 & 0.307 \\
PIC2 & 0.356 & 1.000 & 0.667 & 0.375 & -0.287 & 0.473 & 0.287 \\
PIC3 & 0.250 & 0.667 & 1.000 & 0.303 & -0.096 & 0.293 & 0.542 \\
PIC4 & 0.358 & 0.375 & 0.303 & 1.000 & -0.354 & 0.617 & 0.404 \\
PIC5 & -0.432 & -0.287 & -0.096 & -0.354 & 1.000 & -0.512 & -0.259 \\
PIC6 & 0.431 & 0.473 & 0.293 & 0.617 & -0.512 & 1.000 & 0.351 \\
PIC7 & 0.307 & 0.287 & 0.542 & 0.404 & -0.259 & 0.351 & 1.000 \\
\hline
\end{tabular}

\section{Context}

Inter-item correlation matrix

\begin{tabular}{rrrrrrrr}
\hline \multicolumn{1}{c}{ In1 } & \multicolumn{1}{c}{ CT2 } & \multicolumn{1}{c}{ CT3 } & CT4 & \multicolumn{1}{c}{ CT5 } & CT6 & CT7 \\
\hline CT1 & 1.000 & -0.142 & -0.101 & 0.278 & 0.389 & 0.291 & 0.519 \\
CT2 & -0.142 & 1.000 & 0.105 & 0.440 & -0.166 & 0.137 & 0.087 \\
CT3 & -0.101 & 0.105 & 1.000 & 0.187 & 0.088 & 0.299 & 0.171 \\
CT4 & 0.278 & 0.440 & 0.187 & 1.000 & 0.029 & 0.106 & 0.255 \\
CT5 & 0.389 & -0.166 & 0.088 & 0.029 & 1.000 & 0.143 & 0.077 \\
CT6 & 0.291 & 0.137 & 0.299 & 0.106 & 0.143 & 1.000 & 0.798 \\
CT7 & 0.519 & 0.087 & 0.171 & 0.255 & 0.077 & 0.798 & 1.000 \\
\hline
\end{tabular}

\section{References}

[1] I. Ajzen, The theory of planned behavior, Organizational Behavior and Human Decision Processes 50 (1991), 179-211.

[2] I. Ajzen and M. Fishbein, Understanding Attitudes and Predicting Social Behavior, Prentice-Hall Englewood Cliffs, 1980. 
[3] I. Ajzen and T.J. Madden, Prediction of goal-directed behavior: Attitudes, intentions, and perceived behavioral control, Journal of Experimental Social Psychology 22 (1986), 453-474.

[4] K. Alshare, E. Grandon and D. Miller, Antecedents of computer technology usage: considerations of the technology acceptance model in the academic environment, J Comput Small Coll 19 (2004), 164-180.

[5] M. Asif and J. Krogstie, Mobile Student Information System, Campus-Wide Information Systems (2011), in press.

[6] R.C. Basole, The value and impact of mobile information and communication technologies, in IFAC Symposium on Analysis, Modelling \&amp; Evaluation of Human-Machine Systems, Atlanta GA, USA, 2004.

[7] O. Bohl, S. Manouchehri and U. Winand, Mobile information systems for the private everyday life, Mob Inf Syst 3 (2007), $135-152$.

[8] C. Carlsson, J. Carlsson, K. Hyvonen, J. Puhakainen and P. Walden, Adoption of Mobile Devices/Services - Searching for Answers with the UTAUT, in: Proceedings of the 39th Annual Hawaii International Conference on System Sciences Volume 06, IEEE Computer Society, 2006, p. 132.1.

[9] L.-d. Chen, A model of consumer acceptance of mobile payment, Int J Mob Commun 6 (2008), 32-52.

[10] D.R. Compeau and C.A. Higgins, Computer self-efficacy: development of a measure and initial test, MIS Q 19 (1995), 189-211.

[11] V. Conti, C. Militello, F. Sorbello and S. Vitabile, A multimodal technique for an embedded fingerprint recognizer in mobile payment systems, Mob Inf Syst 5 (2009), 105-124.

[12] L.J. Cronbach, Essentials of Psychological Testing, New York: Harper \&amp; Row, 1984.

[13] L.J. Cronbach and P.E. Meehl, Construct validity in psychological tests, Psychological Bulletin 52 (1955), 281-302.

[14] F.D. Davis, Perceived usefulness, perceived ease of use and user acceptance of information technology, MIS Quarterly 13 (1989), 319-340.

[15] F.D. Davis, R.P. Bagozzi and P.R. Warshaw, User acceptance of computer technology: a comparison of two theoretical models, Manage Sci 35 (1989), 982-1003.

[16] A.K. Dey, Understanding and Using Context, Personal Ubiquitous Comput 5 (2001), 4-7.

[17] A. Durresi and M. Denko, Advances in wireless networks, Mob Inf Syst 5 (2009), 1-3.

[18] S. Figge, Situation-dependent services-a challenge for mobile network operators, Journal of Business Research 57 (2004), 1416-1422.

[19] M. Fishbein and I. Ajzen, Belief, Attitude, Intention and Behavior: An Introduction to Theory and Research, AddisonWesley, 1975.

[20] B. Friedman, J. Peter H. Khan and D.C. Howe, Trust online, Commun ACM 43 (2000), 34-40.

[21] S. Gao and J. Krogstie, The Importance of Context Towards Mobile Services Adoption, in The Fourth International Conference on Mobile Ubiquitous Computing, Systems, Services and Technologies (Ubicomm 2010), Florence, Italy, 2010.

[22] S. Gao, J. Krogstie, and P.A. Gransæther, Mobile Services Acceptance Model, in: Proceedings of the 2008 International Conference on Convergence and Hybrid Information Technology, IEEE Computer Society, Daejeon, Korea, 2008.

[23] D. Gefen, TAM or Just Plain Habit: A Look at Experienced. Online Shoppers, Journal of End User Computing 15 (2003), $1-13$.

[24] J.F. Hair, B. Black, B. Babin, R.E. Anderson and R.L. Tatham, Multivariate Data Analysis, Prentice Hall, 2006.

[25] R.P. Horton, T. Buck, P.E. Waterson and C.W. Clegg, Explaining intranet use with the technology acceptance model, Journal of Information Technology 16 (2001), 237-249.

[26] C. Julien and G.-C. Roman, EgoSpaces: Facilitating Rapid Development of Context-Aware Mobile Applications, IEEE Trans Softw Eng 32 (2006), 281-298.

[27] R. Kalakota and M. Robinson, M-Business: The Race to Mobility, McGraw-Hill, Inc., 2002.

[28] E. Karahanna, D.W. Straub and N.L. Chervany, Information technology adoption across time: a cross-sectional comparison of pre-adoption and post-adoption beliefs, MIS $Q 23$ (1999), 183-213.

[29] B. Kargin and N. Basoglu, Adpotion factoes of Mobile Services, in ICMB 2006, Copenhagen, Denmark, 2006.

[30] P. Katerattanakul and K. Siau, Measuring information quality of web sites: development of an instrument, in: Proceedings of the 20th international conference on Information Systems, Association for Information Systems, Charlotte, North Carolina, United States, 1999.

[31] P. Katerattanakul and K. Siau, Factors affecting the information quality of personal Web portfolios, J Am Soc Inf Sci Technol 59 (2008), 63-76.

[32] J.-O. Kim and C.W. Mueller, Factor Analysis: Statistical Methods and Practical Issues, SAGE Publications, Inc, 1978.

[33] P. Kline, The Handbook of Psychological Testing, Routledge, London, 1993.

[34] A. Kofod-Petersen, P.A. Gransaether and J. Krogstie, An empirical investigation of attitude towards location-aware social network service, Int J Mob Commun 8 (2010), 53-70.

[35] J. Krogstie, Requirements Engineering for Mobile Information Systems, in the Seventh International Workshop on Requirements Engineering: Foundations for Software Quality (REFSQ'01), Interlaken, Switzerland, 2001. 
[36] Y.-F. Kuo and S.-N. Yen, Towards an understanding of the behavioral intention to use 3G mobile value-added services, Comput Hum Behav 25 (2009), 103-110.

[37] A.L. Lederer, D.J. Maupin, M.P. Sena and Y. Zhuang, The technology acceptance model and the World Wide Web, Decis Support Syst 29 (2000), 269-282.

[38] T. Lee and J. Jun, Contextual Perceived Usefulness? Toward an Understanding of Mobile Commerce Acceptance, in: Proceedings of the International Conference on Mobile Business, IEEE Computer Society, 2005.

[39] P. Legris, J. Ingham and P. Collerette, Why do people use information technology?: a critical review of the technology acceptance model, Inf Manage 40 (2003), 191-204.

[40] B.R. Lewis, G.F. Templeton and T.A. Byrd, A methodology for construct development in MIS research, Eur J Inf Syst 14 (2005), 388-400.

[41] C.-H. Liao, C.-W. Tsou and M.-F. Huang, Factors influencing the usage of 3G mobile services in Taiwan, Online Information Review 31 (2007), 759-774.

[42] J.-W. Moon and Y.-G. Kim, Extending the TAM for a World-Wide-Web context, Inf Manage 38 (2001), 217-230.

[43] G.C. Moore and I. Benbasat, Development of an Instrument to Measure the Perceptions of Adopting an Information Technology Innovation, Information Systems Research 2 (1991), 192-222.

[44] F.F.-H. Nah, K. Siau and H. Sheng, The value of mobile applications: a utility company study, Commun ACM 48 (2005), $85-90$.

[45] J.C. Nunnally, Psychometric theory, McGraw-Hill, New York, 1978.

[46] P.A. Pavlou, Consumer Acceptance of Electronic Commerce: Integrating Trust and Risk with the Technology Acceptance Model, Int J Electron Commerce 7 (2003), 101-134.

[47] P. Pedersen and L. Methlie, Understanding Mobile Commerce End-User Adoption: A Triangulation Perspective and Suggestion for an Exploratory Service Evaluation Framework, in: Proceedings of the 35th Annual Hawaii International Conference on System Sciences (HICSS'02)-Volume 3 - Volume 3, IEEE Computer Society, 2002.

[48] J.P. Robinson, P.R. Shaver and L.S. Wrightsman, Criteria for scale selections and evaluation, Academic Press, San Diego, CA, 1991.

[49] E.M. Rogers, The Diffusion of Innovations, Free Press, New York, 1995.

[50] M. Safar, H. Sawwan, M. Taha and T. Al-Fadhli, Virtual social networks online and mobile systems, Mob Inf Syst 5 (2009), 233-253.

[51] H. Sheng, F. Nah and K. Siau, Strategic Implications of Mobile Technology: A Case Study Using Value-Focused Thinking, Journal of Strategic Information Systems 14 (2005), 269-290.

[52] K. Siau, E.-P. Lim and Z. Shen, Mobile Commerce - Promises, Challenges, and. Research Agenda, Journal of Database Management 12 (2001), 4-13.

[53] K. Siau and Z. Shen, Building customer trust in mobile commerce, Commun. ACM 46 (2003), 91-94.

[54] K. Siau and Z. Shen, Mobile communications and mobile services, Int J Mob Commun 1 (2003), 3-14.

[55] D.N. Stone and D.A. Ziebart, A Model of Financial Incentive Effects in Decision Making, Organizational Behavior and Human Decision Processes 61 (1995), 250-261.

[56] D. Straub, Validating instruments in MIS research, MIS Quarterly 13 (1989), 147-169.

[57] S. Taylor and P. Todd, Assessing IT usage: the role of prior experience, MIS $Q 19$ (1995), 561-570.

[58] S. Taylor and P.A. Todd, Understanding Information Technology Usage: A Test of Competing Models, Information Systems Research 6 (1995), 144-176.

[59] R.L. Thompson, C.A. Higgins and J.M. Howell, Personal computing: toward a conceptual model of utilization, $M I S Q$ 15 (1991), 125-143.

[60] H.C. Triandis, Values, attitudes and interpersonal behavior, in Nebraska Symposium Motivation, 1979, Beliefs, Attitudes and Values, Lincoln, US, 1980.

[61] K. Ven and J. Verelst, The Impact of Ideology on the Organizational Adoption of Open Source Software, Journal of Database Management 19 (2008), 58-72.

[62] V. Venkatesh, M.G. Morris, G.B. Davis and F.D. Davis, User Acceptance of Information Technology: Toward a Unified View, MIS Quarterly 27 (2003), 425-478.

[63] L. Viljanen, Towards an Ontology of Trust, in 2nd International conference on Trust, Privacy and Security in Digital Business, 2005, pp. 175-184.

[64] K. Wehmeyer, User-device attachment scale development and initial test, Int J Mob Commun 6 (2008), $280-295$.

[65] J.-H. Wu and S.-C. Wang, What drives mobile commerce? An empirical evaluation of the revised technology acceptance model, Inf Manage 42 (2005), 719-729.

[66] L. Xiao and S. Dasgupta, Dynamic IT capability: An Instrument Development Study, in AMCIS 2009, San Francisco, USA, 2009.

[67] Z. Xu and Y. Yuan, What is the Influence of Context and Incentive on Mobile Commerce Adoption? A Case study of a GPS-based Taxi Dispatching System, in: Proceedings of the International Conference on the Management of Mobile Business, IEEE Computer Society, 2007. 
[68] I. You and T. Hara, Mobile and Wireless Networks, Mob Inf Syst 6 (2010), 1-3.

[69] Y. Yuan and W. Zheng, Mobile Task Characteristics and the Needs for Mobile Work Support: A Comparison between Mobile Knowledge Workers and Field Workers, in International Conference on Mobile Business (ICMB 2009), Dalian, China, 2009.

Shang Gao is a PHD student at the Department of Computer and Information Science at the Norwegian University of Science and Technology (NTNU), Norway. He obtained his master degree (2006) in Engineering and Management of Information Systems from the Royal Institute of Technology (KTH), Sweden. His research interests include mobile information systems, technology diffusion, enterprise modelling, and model-driven development.

John Krogstie holds a PhD (1995) and a MSc (1991) in information systems from the Norwegian University of Science and Technology (NTNU), where he is currently a full professor in information systems. He is also the Vice Dean of the IME-faculty, responsible for the thematic area ICT. John Krogstie is the Norwegian representative for IFIP TC8 and chair of IFIP WG 8.1 on information system design and evaluation. His research interests are information systems modelling, quality of models and modelling languages, eGovernment and mobile information systems. He has published around 150 refereed papers in journals, books and archival proceedings since 1991.

Keng Siau is the E. J. Faulkner Chair Professor of Management Information Systems (MIS) and Full Professor of Management at the University of Nebraska, Lincoln (UNL). He is the Director of the UNL-IBM Global Innovation Hub, Editor-in-Chief of the Journal of Database Management, North America Regional Editor of the Requirements Engineering journal, and Co-Editorin-Chief of the Advances in Database Research series. He received his Ph.D. degree from the University of British Columbia $(U B C)$. His master and bachelor degrees are in Computer and Information Sciences from the National University of Singapore. Professor Siau has over 250 academic publications. He served as the Organizing and Program Chairs of the International Conference on Evaluation of Modeling Methods in Systems Analysis and Design (EMMSAD) (1996 - 2005). He also served on the organizing committees of AMCIS 2005, ER 2006, AMCIS 2007, EuroSIGSAND 2007, EuroSIGSAND 2008, and ICMB 2009. He received the International Federation for Information Processing (IFIP) Outstanding Service Award in 2006, and the IBM Faculty Award in 2006 and 2008. 

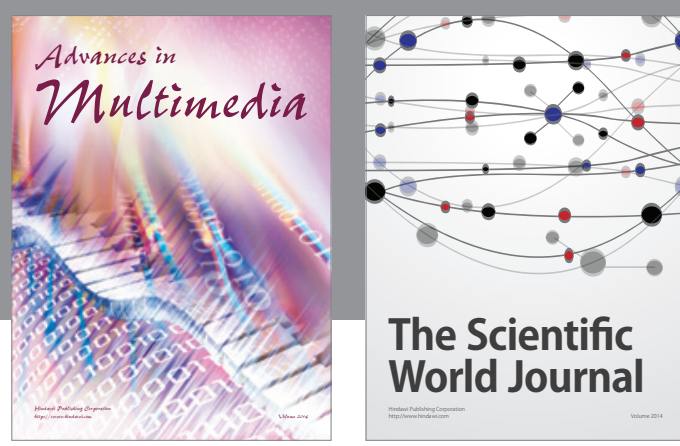

The Scientific World Journal
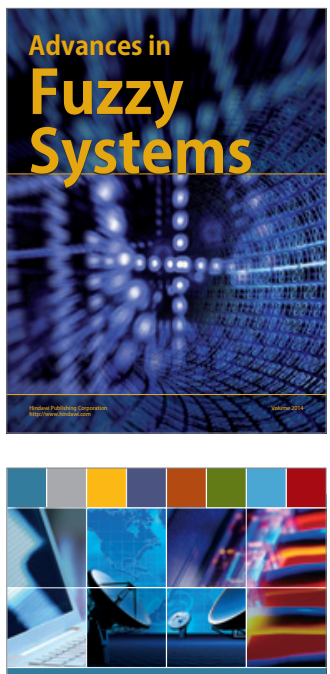

Computer Networks and Communications
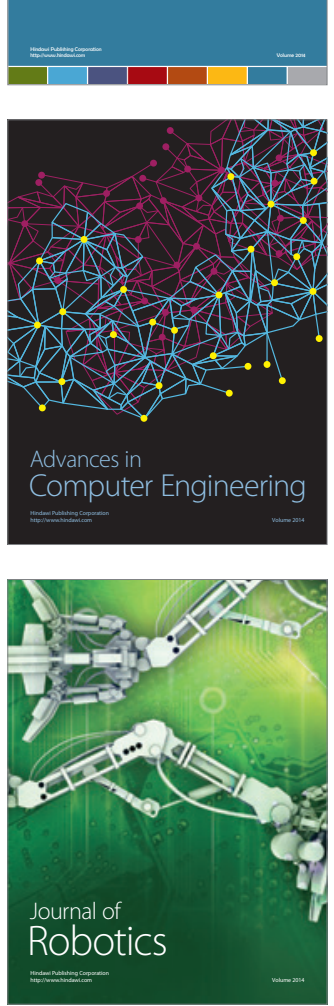
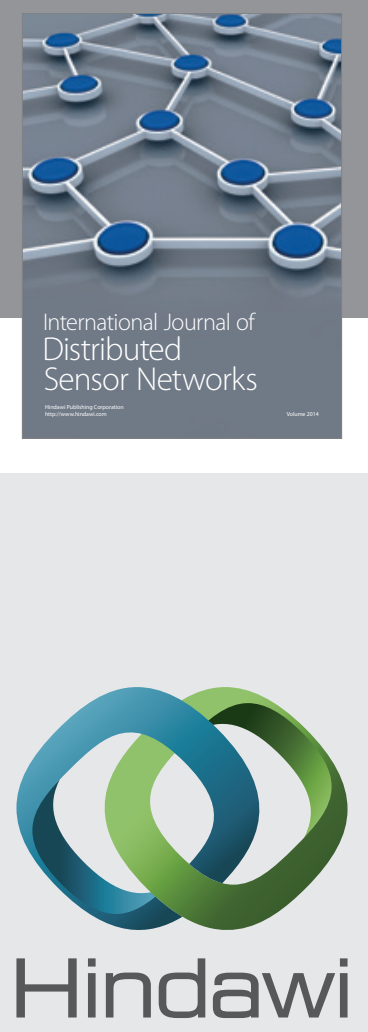

Submit your manuscripts at

http://www.hindawi.com
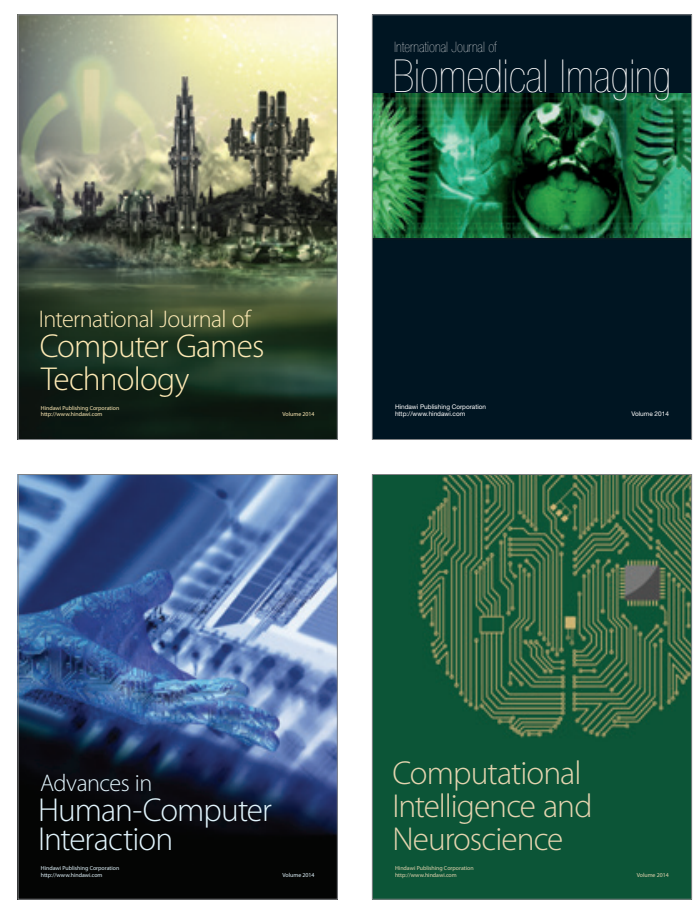
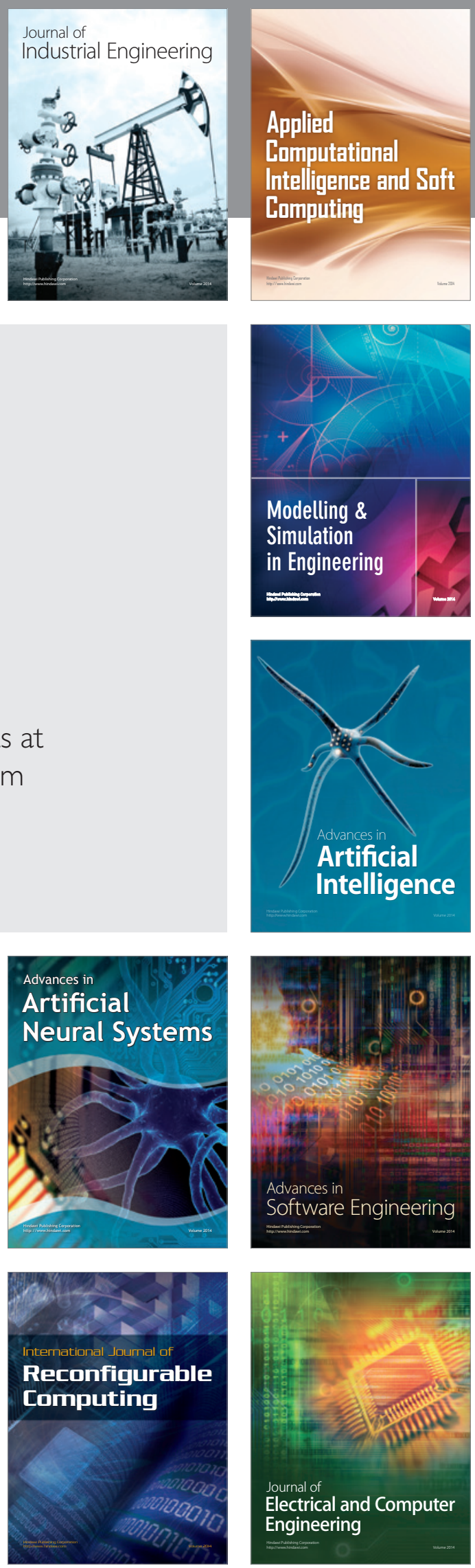